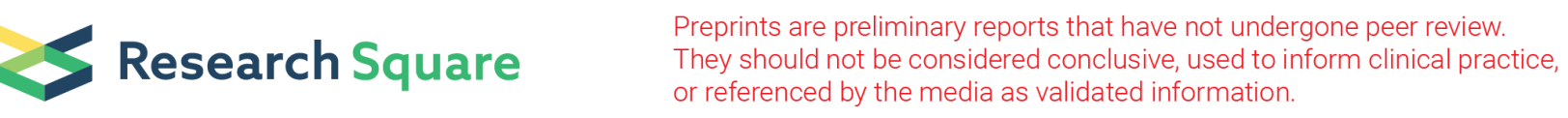

\title{
Awareness and practice of standard precautions among Kerala State Health Services personnel in Neyyattinkara
}

\section{Veena Saroji H}

Sree Chitra Tirunal Institute for Medical Sciences and Technology

Srinivasan Kannan ( $\sim$ kannansrini@ymail.com )

Sree Chitra Tirunal Institute for Medical Sciences and Technology https://orcid.org/0000-0003-27319428

\section{Research Article}

Keywords: Standard precautions, infection control, awareness, practice, quality

Posted Date: September 27th, 2021

DOI: https://doi.org/10.21203/rs.3.rs-941936/v1

License: (c) (i) This work is licensed under a Creative Commons Attribution 4.0 International License.

Read Full License 


\section{Abstract}

Introduction: Standard precautions are the basic infection control precautions that should be followed in any setting where health care is delivered. This study aims to determine the level of awareness and practice of standard precautions among health personnel, factors that influence practice and the possible hindrances in practice of the same.

Methodology: This cross-sectional study was done using a structured interview schedule among 78 doctors, 151 nurses, 80 nursing assistants and 16 lab technicians working in the State health service institutions of Neyyattinkara Taluk. SPSS version 21 software was used for analysis.

Results: The findings of the study show that 86.5 percent of the health care personnel (HCP) had good awareness in hand hygiene (HH), 64 percent in use of personal protective equipment (PPE), 78.8 percent in respiratory hygiene $(\mathrm{RH}), 93.5$ percent in safe injection practices (SIP) and 18.5 percent in waste disposal and decontamination (WD). Good practice was seen in 9.2percent of HCP for $\mathrm{HH}, 69.5$ percent in $\mathrm{PPE}, 94.2$ percent in $\mathrm{RH}, 86.8$ percent\% in SIP and 97.8percent for WD respectively. When all elements were analysed together nurses were the most likely to have good awareness $(15.9 \%)$ and doctors were the most likely to have good practice (8.97\%). Significant association was noted between age and awareness in $\mathrm{HH}(p=0.012)$ and $\mathrm{RH}(\mathrm{p}=0.049)$, between availability of resources and practice in $\mathrm{RH}(\mathrm{p}=0.004)$, $\operatorname{PPE}(\mathrm{p}=0.042)$ and $\mathrm{HH}(\mathrm{p}=0.045)$ and between trainings received and practice in $\mathrm{RH}(\mathrm{p}=0.037)$. Hepatitis $\mathrm{B}$ vaccination was taken by 68.6 percent of respondents only

Conclusion: Awareness and practice of standard precautions are much deficient among the study population. Trainings and availability of resources have some positive effect in practice. Training coverage and Hepatitis B vaccination coverage were deficient. The needs for extensive trainings and for making the resources available are suggested.

\section{Introduction}

'Standard Precautions' are the minimum infection prevention practices that apply to all patient care, in any setting where healthcare is delivered.(1) The 'Standard Precautions' concept replaced the earlier Universal precaution in 1996.(2) Standard Precautionary Measures are a set of infection control practices used to prevent infection from the health personnel to the patients and caregivers and vice versa. $(3,4)$ When health professionals do not follow infection control measures then the health care settings will be a source for infections and at times it may also be a cause for outbreaks in the community. $(5,6)$

Strict instructions and training are given to all categories of staff in the healthcare systems and settings worldwide. However, many health care providers do not seem to follow these precautions. A literature review by Gammon J et al, for compliance of healthcare workers to standard precautions reported internationally prevalent suboptimal compliance to infection control precautions. There was also evidence suggesting the compliance to each aspects of standard precaution varied, and the health workers followed only few of the standard practices.(7) Low compliance to standard precautionary 
measures in healthcare settings have serious consequences, including the spread of infectious diseases like HIV, Nipah(8), Ebola(9), and Marburg.

Both the patients and health care providers are at risk for Healthcare-Associated Infections. HealthcareAssociated Infections affect hundreds of millions of patients each year, and most of these are preventable.(6) The chance of getting a HIV infection after a prick from an infected person is $0.3 \%$, Hepatitis $C$ virus is $1.8 \%$, and Hepatitis $B$ virus infection ranges from $6 \%-30 \%$ respectively.(10)

Translation of the precautionary guidelines into practice has been studied in varied health care settings. Many of the studies based on observing the healthcare providers in field or simulated settings have reported breaching(11), and low complianceof standard precautions.(12). The poor compliance persists in the different service sectors in health care delivery. An evaluation of Clinical laboratories in Karachi, Pakistan, on adherence to standard precautions using an observational checklist revealed the non-usage of gloves, protective gowns, and disinfectants, as well as the non-availability of needle cutters, and incinerators in majority of the laboratories evaluated.(13)

Knowledge-Practice surveys of healthcare workers have also reported low levels of understanding(14), and practice(15) of the standard precautions, or Universal Precautions. Review of Needle Stick Injuries (NSIs) in a tertiary level hospital in Tamil Nadu, India, reported that more $25 \%$ of the NSIs were caused by the recapping of needles, and other improper disposal of the sharps.(16) It is also documented that longer duration of practice in health sector is associated with higher compliance to the precautionary measures.(14)

In Kerala, the infection control policy in health care is an integrated, mandatory policy under the quality assurance programme - Kerala Accreditation Standards for Hospitals (KASH).(17) The KASH standards set criteria for accreditation of all levels of healthcare organizations in the state from Primary Health Centres, to District Hospitals, General Hospitals, and Speciality Hospitals, and are based on global benchmarks for ensuring safe, quality health care, with due importance given to infection control.(17) It has been established that awareness is only the base, and it is the practice of standard Precautions that can reduce the load of Health Care Associated Infections. Though there are a lot of studies conducted on practice of standard precautions in other countries, studies in Indian context are limited. There is also a dearth of published data on the Kerala context.

The present study focuses to study the level of awareness and practice of these precautionary measures and the factors hindering the practices among health personnel in Neyyattinkara Taluk, Thiruvananthapuram district.

\section{Materials And Methods}

The present study was of a cross sectional study design. The study was conducted among all institutions under the State Health Services in Neyyattinkara Taluk of Thiruvananthapuram district, Kerala State. Four categories of health providers from various Institutions under the State Health Services in Neyyattinkara 
Taluk in Thiruvananthapuram district of Kerala State were studied. The four categories include doctors, staff nurse, nursing assistants and lab technicians. There were 15 Primary Health Centres, 6 Community Health Centres, 1 Taluk hospital and 1 General hospital, making a total of 23 institutions under the Neyyattinkara Taluk area. The health care providers included 94 doctors, 243 nurses, 99 nursing assistants and 16 lab technicians, making a total of 452 healthcare providers.

Stratified random sampling of the four categories of health personnel was used, and a total sample of 325 was calculated $\left(n=4 p q / d^{2}\right)$ [Table 1].

\section{Table 1. Sampling frame}

\begin{tabular}{|lll|}
\hline Category & Population Size & Sample Size \\
\hline Doctors & 94 & 78 \\
\hline Staff Nurses & 243 & 151 \\
\hline Nursing Assistants & 99 & 80 \\
\hline Lab Technicians & 16 & 16 \\
\hline Total & 452 & 325 \\
\hline
\end{tabular}

Those who had joined the service within six months were excluded from the study.

The data was collected through a structured interview schedule focussing on the awareness and practice of standard precautions among the health personnel.

The data collection was done from June 16 th to August $31^{\text {st }}$ of 2014 , by the principal investigator. The permission from the Director of Health Services was obtained. Permission from the respective superintendents was taken prior to data collection. The list of the health personnel was also taken from the respective superintendents. From the list a stratified random sample of four categories of health personnel who did not fit in to the exclusion criteria were included. The interview schedule and the consent form had been translated to the local language Malayalam. The interview schedule had been back translated and tested for content validity. The staff nurses, lab technicians and nursing assistants were interviewed using Malayalam schedule. An informed consent was obtained prior to the interview. Privacy and confidentiality of all the informants was maintained. Interviews were performed in the respective institutions at a place and time convenient for the informant and the investigator, without causing any hindrances to their daily routine. The collected data was stored and used for analysis. Univariate and bivariate analyses were conducted using SPSS version 21. The study was conducted after obtaining ethical clearance from the Institutional Ethics Committee. The informant had the freedom to deny answering any questions.

\section{Results}




\section{Characteristics of the Study Population}

Mean age of respondents was $40.54 \pm 9.3$ years and $74.5 \%$ were females. The mean years of service was 10.64 years which was nearly same among the four groups. Only $82.5 \%$ of the subjects had received any training and only $33.8 \%$ received training in standard precautions. Infection control protocol was followed by $82.5 \%$ of the population. Hepatitis B vaccination coverage was only $68.6 \%$.

There was significant association for profession with training received and hepatitis $B$ vaccination status. Doctors had received the most training in infection control. Hepatitis $B$ vaccination coverage was highest among doctors.

The essential resources readily available in the institutions where the respondents worked were gloves (94.8\%) puncture free containers (86.5\%), colour coded bags (77.8\%) and signboards (71\%). Alcohol based hand rub $(9.2 \%)$ and safe receptacles $(0.9 \%)$ were least available.

\section{Distribution of Awareness and Practice in Standard Precautions}

Good awareness in standard precautions was found in $11.38 \%$ only and in $15.9 \%$ of nurses which was the highest across various professions. Among doctors it was much lower (5.1\%). No lab technician had answered all the questions correctly. When considered separately, most respondents had good awareness in safe injection practices and the least in waste disposal. The results of analysis is represented in Fig. 1.

Good practice was seen only in $5.5 \%$ of respondents and in $8.97 \%$ of doctors which was the highest across various professions. The analysis of practice of individual elements is represented in Fig 2.

\section{Awareness on Standard Precautions:}

It was found that as age increased good awareness in hand hygiene also increased. Profession had significant association with good awareness of hand hygiene. Nursing assistants were the most to have good awareness in hand hygiene (97.5\%). Doctors (91\%) and nurses $(82.1 \%)$ were comparable. But only half of the lab technicians were having good awareness.

Nursing assistants were the most to have good awareness on use of PPE (78.75\%) and on safe injection practices $(98.75 \%)$ which were both significant. Age had significant association on respiratory hygiene. The study respondents between 35 and 44 years were more likely to have good awareness on respiratory hygiene (86.73\%).

\section{Practice of Standard Precautions:}

There was significant positive association for profession, training received and availability of resources with good practice of hand hygiene. Doctors were the most likely to have good practice. Table 2 . The association between independent variables and practice of PPE is detailed in the table 3 and that of safe injection practices is represented in Table 4. 
There was significant association for profession, availability of resources and training received with practice of respiratory hygiene. Nurses were the most likely to have good practice (98\%). Table 5 . Result of bivariate analysis on practice on waste disposal is represented in Table 6.

Table 2. Bivariate Analysis regarding practice on hand hygiene as outcome variable

\begin{tabular}{|c|c|c|c|c|}
\hline Variable name & & $\mathrm{N}$ & Good practice & $P$ value \\
\hline \multirow[t]{5}{*}{ Age } & $<24$ & 6 & 0 & 0.178 \\
\hline & $25-34$ & 99 & $4(4.04)$ & \\
\hline & $35-44$ & 98 & $10(10.20)$ & \\
\hline & $45-54$ & 110 & $14(12.73)$ & \\
\hline & $>54$ & 12 & $2(16.67)$ & \\
\hline \multirow[t]{2}{*}{ Sex } & Male & 82 & $11(13.41)$ & 0.130 \\
\hline & Female & 243 & 19(7.82) & \\
\hline \multirow[t]{4}{*}{ Profession } & Doctor & 78 & 12(15.38) & 0.030 \\
\hline & Nurse & 151 & $8(5.3)$ & \\
\hline & NA & 80 & $10(12.5)$ & \\
\hline & Lab Tech & 16 & 0 & \\
\hline Training Received & Yes & 238 & $26(10.92)$ & 0.081 \\
\hline Std Precaution/HIV & No & 87 & $4(4.6)$ & \\
\hline \multirow[t]{3}{*}{ Total service in years } & $1 / 2-10$ & 195 & $14(7.2)$ & 0.273 \\
\hline & $11-20$ & 94 & 11(11.7) & \\
\hline & $>20$ & 36 & $5(13.9)$ & \\
\hline \multirow[t]{2}{*}{ Specific protocol in use } & Yes & 268 & $21(7.84)$ & 0.060 \\
\hline & No & 57 & $9(15.79)$ & \\
\hline Availability of resources & Yes & 30 & $6(20)$ & 0.045 \\
\hline (ABHR) & No & 295 & $24(8.14)$ & \\
\hline
\end{tabular}

Table 3. Bivariate analysis regarding practice on use of PPE 


\begin{tabular}{|c|c|c|c|c|}
\hline Variable name & & $\mathrm{N}$ & Good practice & $P$ value \\
\hline \multirow[t]{5}{*}{ Age } & $<24$ & 6 & $3(50)$ & 0.735 \\
\hline & $25-34$ & 99 & $67(67.68)$ & \\
\hline & $35-44$ & 98 & $67(68.37)$ & \\
\hline & $45-54$ & 110 & $80(72.73)$ & \\
\hline & $>54$ & 12 & $9(75)$ & \\
\hline \multirow[t]{2}{*}{ Sex } & Male & 82 & $53(64.63)$ & 0.264 \\
\hline & Female & 243 & $173(71.2)$ & \\
\hline \multirow[t]{4}{*}{ Profession } & Doctor & 78 & $51(65.38)$ & 0.199 \\
\hline & Nurse & 151 & $111(73.51)$ & \\
\hline & NA & 80 & $56(70)$ & \\
\hline & Lab Tech & 16 & $8(50)$ & \\
\hline Training Received & Yes & 238 & $170(71.42)$ & 0.221 \\
\hline Std Precaution/HIV & No & 87 & $56(64.37)$ & \\
\hline \multirow[t]{3}{*}{ Total service in years } & $1 / 2-10$ & 195 & $127(65.1)$ & 0.058 \\
\hline & $11-20$ & 94 & $69(73.4)$ & \\
\hline & $>20$ & 36 & $30(83.3)$ & \\
\hline \multirow[t]{2}{*}{ Specific protocol in use } & Yes & 268 & 190(70.9) & 0.239 \\
\hline & No & 57 & $36(63.15)$ & \\
\hline \multirow[t]{2}{*}{ Availability of resources } & Yes & 138 & $104(75.4)$ & 0.324 \\
\hline & No & 187 & $122(65.24)$ & \\
\hline
\end{tabular}

Table 4. Bivariate analysis regarding practice of SIP 


\begin{tabular}{|c|c|c|c|c|}
\hline Variable name & & $\mathrm{N}$ & Good practice & $P$ value \\
\hline \multirow[t]{5}{*}{ Age } & $<24$ & 6 & $4(66.67)$ & 0.154 \\
\hline & $25-34$ & 99 & $82(82.83)$ & \\
\hline & $35-44$ & 98 & $88(89.8)$ & \\
\hline & $45-54$ & 110 & $99(90)$ & \\
\hline & $>54$ & 12 & $9(75)$ & \\
\hline \multirow[t]{2}{*}{ Sex } & Male & 82 & $76(92.69)$ & 0.068 \\
\hline & Female & 243 & 206(84.77) & \\
\hline \multirow[t]{4}{*}{ Profession } & Doctor & 78 & $75(96.15)$ & 0.006 \\
\hline & Nurse & 151 & $121(80.13)$ & \\
\hline & NA & 80 & $72(90)$ & \\
\hline & Lab Tech & 16 & $14(87.5)$ & \\
\hline Training Received & Yes & 238 & $211(88.66)$ & 0.097 \\
\hline Std Precaution/HIV & No & 87 & $71(81.61)$ & \\
\hline \multirow[t]{3}{*}{ Total service in years } & $1 / 2-10$ & 195 & $167(85.6)$ & 0.909 \\
\hline & $11-20$ & 94 & $83(88.3)$ & \\
\hline & $>20$ & 36 & $32(88.9)$ & \\
\hline \multirow[t]{2}{*}{ Specific protocol in use } & Yes & 268 & 235(87.69) & 0.290 \\
\hline & No & 57 & $47(82.46)$ & \\
\hline \multirow[t]{2}{*}{ Availability of resources } & Yes & 281 & $246(87.5)$ & 0.297 \\
\hline & No & 44 & $36(81.8)$ & \\
\hline
\end{tabular}

Table 5. Bivariate analysis regarding practice of respiratory hygiene 


\begin{tabular}{|lllll|}
\hline Variable name & & N & Good practice & P value \\
\hline Age & $<24$ & 6 & $6(100)$ & \\
& $25-34$ & 99 & $92(92.93)$ & 0.506 \\
& $35-44$ & 98 & $90(91.84)$ & \\
& $45-54$ & 110 & $106(96.36)$ & \\
& $>54$ & 12 & 0 & \\
\hline Sex & Male & 82 & $77(93.9)$ & 0.911 \\
& Female & 243 & $229(94.24)$ & \\
\hline Profession & Doctor & 78 & $67(85.9)$ & $<0.001$ \\
& Nurse & 151 & $148(98)$ & \\
& NA & 80 & $78(97.5)$ & \\
\hline Training Received & Yab Tech & 16 & $13(81.25)$ & \\
Std Precaution/HIV & No & 87 & $78(89.66)$ & \\
\hline Total service in years & $1 / 2-10$ & 195 & $182(93.3)$ & 0.637 \\
& $11-20$ & 94 & $89(94.7)$ & \\
\hline Specific protocol in use & Yes & 268 & $254(94.78)$ & 0.300 \\
\hline No & No & 57 & $52(91.22)$ & \\
\hline & Yes & 231 & $223(96.5)$ & 0.004 \\
& No & 94 & $83(88.3)$ & \\
\hline
\end{tabular}

Table 6. Bivariate analysis regarding practice of waste disposal 


\begin{tabular}{|c|c|c|c|c|}
\hline Variable name & & $\mathrm{N}$ & Good practice & $P$ value \\
\hline \multirow[t]{5}{*}{ Age } & $<24$ & 6 & $6(100)$ & 0.965 \\
\hline & $25-34$ & 99 & $97(97.98)$ & \\
\hline & $35-44$ & 98 & $96(97.96)$ & \\
\hline & $45-54$ & 110 & 107(97.27) & \\
\hline & $>54$ & 12 & 12(100) & \\
\hline \multirow[t]{2}{*}{ Sex } & Male & 82 & $81(98.78)$ & 0.500 \\
\hline & Female & 243 & 237(97.53) & \\
\hline \multirow[t]{4}{*}{ Profession } & Doctor & 78 & $77(98.72)$ & 0.564 \\
\hline & Nurse & 151 & $147(97.35)$ & \\
\hline & NA & 80 & $79(98.75)$ & \\
\hline & Lab Tech & 16 & 15(93.85) & \\
\hline Training Received & Yes & 238 & 232(97.48) & 0.451 \\
\hline Std Precaution/HIV & No & 87 & $86(98.85)$ & \\
\hline \multirow[t]{3}{*}{ Total service in years } & $1 / 2-10$ & 195 & 190(97.4) & 0.622 \\
\hline & $11-20$ & 94 & $92(97.9)$ & \\
\hline & $>20$ & 36 & $36(100)$ & \\
\hline \multirow[t]{2}{*}{ Specific protocol in use } & Yes & 268 & 262(97.76) & 0.819 \\
\hline & No & 51 & $56(98.25)$ & \\
\hline \multirow[t]{2}{*}{ Availability of resources } & Yes & 224 & $220(98.2)$ & 0.68 \\
\hline & No & 101 & $98(97)$ & \\
\hline
\end{tabular}

\section{Discussion}

\section{Level of awareness and practice in Standard Precautions}

Good awareness in standard precautions was found in $11.38 \%$ only. Among doctors, it was still lower $(5.1 \%)$ and no lab technician could answer all the questions correctly. These findings are in line with a 2012 Nigerian study, by Abdulraheem et al, where only $13 \%$ of the respondents had adequate knowledge of universal precautions.(18) But the findings are in contrast to a 2013 French study, which showed that $39.3 \%$ of subjects had good knowledge of standard precautions.(19) The difference could 
be due to the background settings, as the present study and the Nigerian study took place in public sector institutions in low- and middle-income countries, where health care spending is significantly lower than that of a high-income country like France.(20)

Good awareness was seen the most among nurses (15.9\%), and Nursing Assistants (11.3\%), similar to a study in Jamaica, where more nurses were very knowledgeable of the universal precautions than the respondents in other job categories.(21)

The respondents, in general, exhibited varying levels of awareness in the different elements of standard precautions. In hand hygiene $86.5 \%$ had good awareness, which was in line with a Nigerian study(22) where it was $83 \%$. Good awareness in personal protective equipment use was found in $64 \%$ of the respondents, cough hygiene in $78.8 \%$ and safe injection practices in $93.5 \%$. This points to the relative importance given by the health personnel to each precautionary element. Importance of self-protection, and respiratory hygiene has been underestimated by the staff, and the sensitizations and job-trainings in these aspects of the standard precautions are not having the desired impact.

It was also noted that the respondents in different job-categories had varying levels of knowledge in the different aspects of the standard precautions. Nurses were the most to have good awareness in waste disposal and decontamination (24.5\%). Nursing assistants were the most to have good awareness in hand hygiene (97.5\%), use of PPE (78.8\%), safe injection practices (98.8\%), and respiratory hygiene (82.3\%). Doctors had better awareness in hand hygiene (91\%), and respiratory hygiene (80.8\%), than use of PPE (51.3\%), safe injection practices (84.6\%), while lab technicians exhibited better awareness of safe injection practices (75\%), use of PPE (56.3\%), and respiratory hygiene $(56.3 \%)$, and least in waste disposal (6.25\%). This shows that the awareness of the respondents tends to be more on the aspects of standard precautions which they put into practice more in relation to their routine duties.

Good practice is seen in $5.5 \%$ of respondents, similar to a recent Ethiopian study.(23) Good practice in personal protective equipment use, cough hygiene, safe injection practices and waste disposal were seen in $69.5 \%, 94.2 \%, 86.8 \%$ and $97.8 \%$ respectively. Only $9.2 \%$ had good practice in hand hygiene which is in line with a study from Kolkata which showed only $12.5 \%$ washed their hands before injection.

Doctors were most likely to have good practice (8.97\%), whereas none of the lab technicians had good practice in standard precautions. Doctors were the most likely to have good practice in hand hygiene $(15.4 \%)$ and safe injection practices (96.15\%) when the components are taken separately. Nurses were the most likely to have good practice in cough hygiene (98\%) and PPE use (73.5\%) which confirms a Jamaican study in which more frequent use of protective equipment was seen among nurses.(21)

\subsection{Factors affecting Practice}

Good practice of hand hygiene was seen more towards older age groups and among males. Training received, length of service and availability of resources also had positive association. These 
findings are in confirmation with a 2002 Geneva study which showed that availability of alcohol-based hand rubs increased hand hygiene compliance.(25)

Good practice in PPE use also increased with age. Female gender, training received length of service and availability of resources also had positive association. This finding is in line with a Jamaican study by Vaz et al.(21)

Good practice in SIP is similar to that in hand hygiene as there is positive association with increasing age, male sex, training received, increase in total years of service, specific protocol uses and availability of resources.

There was significant association for training attendance and availability of resources with practice of respiratory hygiene. Practice of respiratory hygiene and waste disposal and decontamination was also almost equal among different age groups and between the two sexes. Use of specific protocol and availability of resources both had positive association with good practice of waste disposal.

\section{Hindrances to Practice}

There was a positive effect for availability of resources on practice of standard precautions. So, lack of these resources was a hindrance to the practice of standard precaution. The essential resources readily available were gloves $(94.8 \%)$ puncture free containers $(86.5 \%)$, colour coded bags $(77.8 \%)$ and signboards $(71 \%)$. Alcohol based hand rub $(9.2 \%)$ and safe receptacles $(0.9 \%)$ were least available. This could be one of the reasons due to which good awareness in hand hygiene was not reflected in the practice.

\section{Other Findings}

Significant positive association was noted between increasing age and awareness in respiratory hygiene and hand hygiene. There was significant association between profession and training attendance. Trainings in standard precautions and blood safety were more likely to be attended by lab technicians.

The Hepatitis B vaccination was taken by $68.6 \%$ of respondents only. This was comparable with the findings of a study among nurses in Kolkata where only about $52.5 \%$ respondents were protected by hepatitis B vaccination(24). Doctors were most likely to be vaccinated (97.4\%). Only $33.7 \%$ of nursing assistants were vaccinated.

\section{Strengths And Limitations Of The Study}

The study included four categories of health personnel from four different types of health care settings. The response rate across the four categories was complete. The collection of data was done entirely by direct interview by the same investigator to reduce bias. 
This study is limited to the Public sector institutions in one Taluk, so the results may not be generalised. Also, the data was collected purely by subjective means.

\section{Conclusion}

The study revealed that awareness, and practice of standard precautionary measure were only $11.38 \%$, and $5.5 \%$ respectively, but the relative awareness and practice in individual aspects of the standard precautions varied the job category, availability of resources, and training obtained. It was seen that good awareness on certain aspects of the standard precautions were not translated into practice due to unavailability of resources that will facilitate the practice. It was also observed that availability of resources like protocols, signboards etc made up for the comparatively low awareness of some other aspects to some extent and facilitated the practice of these measures. In light of these findings, it can be concluded that the trainings on standard precautions to the health personnel needs to be reviewed to suit each job category, and adequate resources be made available in the health care settings to ensure good awareness and practice of the standard precautions.

\section{Declarations}

Conflict of Interest: There is no conflict of interest.

\section{References}

1. CDC. Guide to Infection Prevention for Outpatient Settings: Minimum Expectations for Safe Care [Internet]. Centers for Disease Control and Prevention; 2016 [cited 2021 Sep 9]. Available from: https://www.cdc.gov/infectioncontrol/pdf/outpatient/guide.pdf

2. Bjerke N. Standard Precautions [Internet]. 2002. Available from: https://www.infectioncontroltoday.com

3. WHO. Standard precautions in health care [Internet]. WHO; 2007. Available from: https://www.who.int/csr/resources/publications/EPR_AM2_E7.pdf

4. World Health Organization, editor. WHO guidelines on hand hygiene in health care: first global patient safety challenge: clean care is safer care. Geneva, Switzerland: World Health Organization, Patient Safety; 2009. 262 p.

5. WHO. Emergencies preparedness, response [Internet]. Emergencies preparedness, response. [cited 2014 Feb 12]. Available from: https://www.who.int/csr/bioriskreduction/infection_control/activities/en

6. WHO. Report on the Burden of Endemic Health Care-Associated Infection Worldwide [Internet]. WHO; 2011. Available from: https://apps.who.int/iris/bitstream/handle/10665/80135/9789241501507_eng.pdf?sequence=1

7. Gammon J, Morgan-Samuel H, Gould D. A review of the evidence for suboptimal compliance of healthcare practitioners to standard/universal infection control precautions. J Clin Nurs. 2007 
Mar;0(0):070621074500057-???

8. Arunkumar G, Chandni R, Mourya DT, Singh SK, Sadanandan R, Sudan P, et al. Outbreak Investigation of Nipah Virus Disease in Kerala, India, 2018. The Journal of Infectious Diseases. 2019 May 24;219(12):1867-78.

9. Ebola virus disease [Internet]. [cited 2021 Sep 9]. Available from:

https://www.who.int/westernpacific/health-topics/ebola

10. GA0-01-60R Needlestick Prevention, United States General Accounting Office. Occupational Safety: Selected Cost and Benefit Implications of Needlestick Prevention Devices for Hospitals [Internet]. 2000 [cited 2021 Sep 27]. Available from: https://www.gao.gov/assets/gao-01-60r.pdf

11. Beam EL, Gibbs SG, Boulter KC, Beckerdite ME, Smith PW. A method for evaluating health care workers' personal protective equipment technique. American Journal of Infection Control. 2011 Jun;39(5):415-20.

12. Suchitra J, Lakshmidevi N. Hand washing Compliance - Is It A Reality? [Internet]. Bevinje DSK, Baliga DS, editors. Vol. 5, Online Journal Of Health And Allied Sciences. Dr. B.S. Kakkilaya; 2007. Available from: http://cogprints.org/5494/

13. Mujeeb SA, Adil MM, Altaf A, Shah SA, Luby S. Infection Control Practices in Clinical Laboratories in Pakistan. Infect Control Hosp Epidemiol. 2003 Feb;24(2):141-2.

14. Kermode M, Jolley D, Langkham B, Thomas MS, Holmes W, Gifford SM. Compliance with Universal/Standard Precautions among health care workers in rural north India. American Journal of Infection Control. 2005 Feb;33(1):27-33.

15. Askarian M, McLaws M-L, Meylan M. Knowledge, attitude, and practices related to standard precautions of surgeons and physicians in university-affiliated hospitals of Shiraz, Iran. International Journal of Infectious Diseases. 2007 May;11(3):213-9.

16. Jayanth ST, Kirupakaran H, Brahmadathan KN, Gnanaraj L, Kang G. Needle stick injuries in a tertiary care hospital. Indian J Med Microbiol. 2009 Mar;27(1):44-7.

17. NRHM D. Kerala_Accreditation_Standards_for_Hospitals_Second_Edition.pdf [Internet]. Google Docs. [cited 2021 Sep 9]. Available from:

https://drive.google.com/file/d/1yEAAqpB1vs6CvwSh_IhRNak0RyWwsECP/view? usp=drive_open\&usp=embed_facebook

18. Abdulraheem I, Amodu M, Bolarinwa O, Uthman M. Knowledge, Awareness and Compliance with Standard Precautions among Health Workers in North Eastearn Nigeria. J Community Med Health Edu [Internet]. 2012 [cited 2021 Sep 9];02(03). Available from: https://www.omicsonline.org/knowledge-awareness-and-compliance-with-standard-precautionsamong-health-workers-in-north-eastearn-nigeria-2161-0711.1000131.php?aid=5305

19. Atif ML, Brenet A, Hageaux S, Fave MH, Cochet C, Baticle E, et al. Awareness of standard precautions for 4439 healthcare professionals in 34 institutions in France. Médecine et Maladies Infectieuses. 2013 Jan;43(1):10-6. 
20. WHO. Global Health Expenditure Database [Internet]. Global Health Expenditure Database. 2018 [cited 2021 Sep 27]. Available from: Global Health Expenditure Database

21. Vaz K, McGrowder D, Alexander-Lindo R, Gordon L, Brown P, Irving R. Knowledge, awareness and compliance with universal precautions among health care workers at the University Hospital of the West Indies, Jamaica. Int J Occup Environ Med. 2010 Oct;1(4):171-81.

22. Timothy Ekwere, Ifeoma Okafor. Hand hygiene knowledge and practices among healthcare providers in a tertiary hospital, south west, Nigeria. IJIC [Internet]. 2013 Oct 17 [cited 2021 Sep 26];9(4). Available from: https://www.ijic.info/article/view/11917

23. Yemane D. Standard Precautions Practice among Health Care Workers in Public Health Facilities of Mekelle Special Zone, Northern Ethiopia. J Community Med Health Educ [Internet]. 2014 [cited 2021 Sep 27];04(03). Available from: https://www.omicsonline.org/open-access/standard-precautionspractice-among-health-care-workers-in-public-health-facilities-of-mekelle-special-zone-northernethiopia-2161-0711.1000286. php?aid=26319

24. Paul B, Roy S, Chattopadhyay D, Bisoi S, Misra R, Bhattacharya N, et al. A Study on Safe Injection Practices of Nursing Personnel in a Tertiary Care Hospital of Kolkata, West Bengal, India. TAF Prev Med Bull. 2011;10(6):681.

25. Hugonnet S, Perneger TV, Pittet D. Alcohol-Based Handrub Improves Compliance With Hand Hygiene in Intensive Care Units. Arch Intern Med. 2002 May 13;162(9):1037.

\section{Figures}

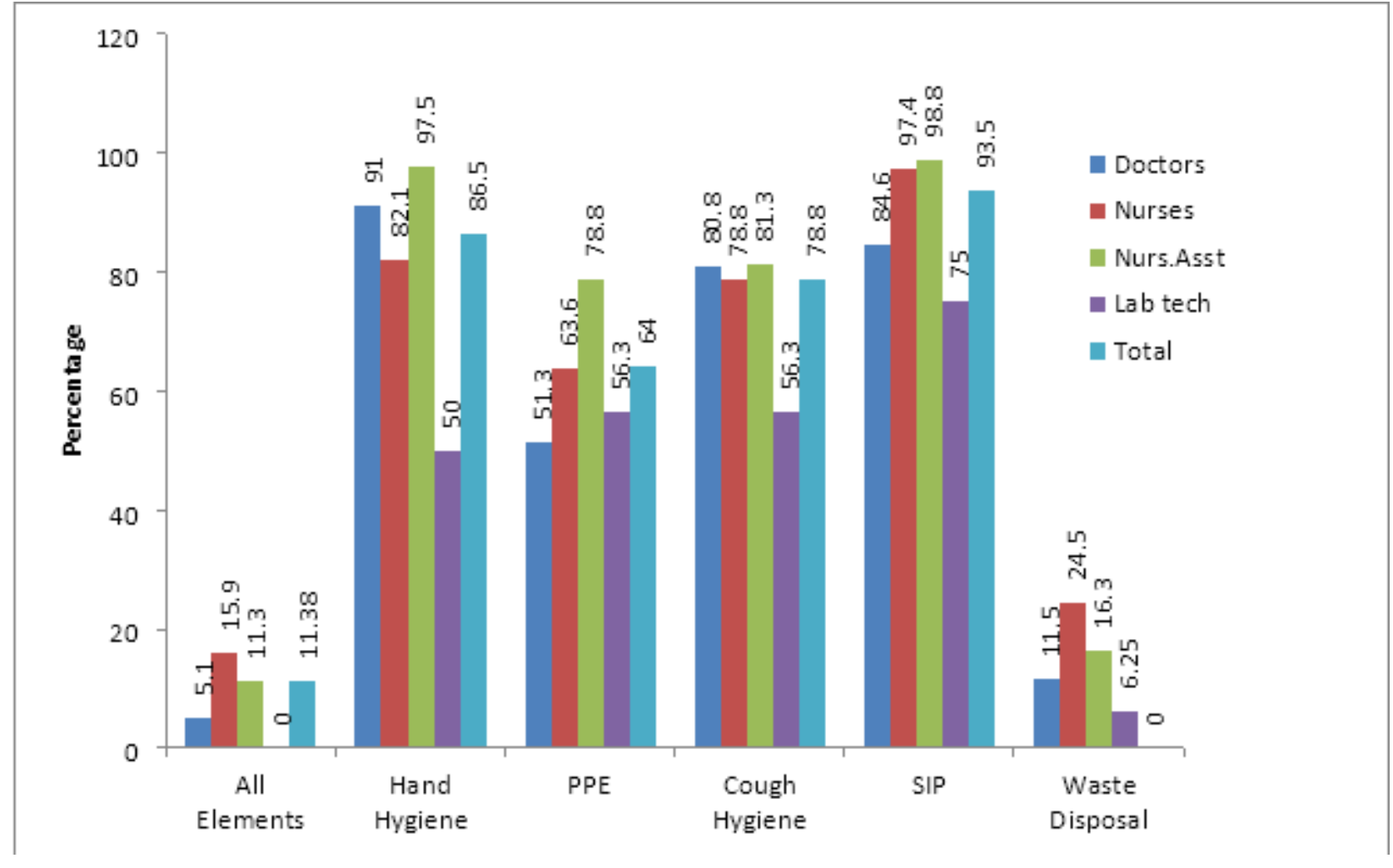




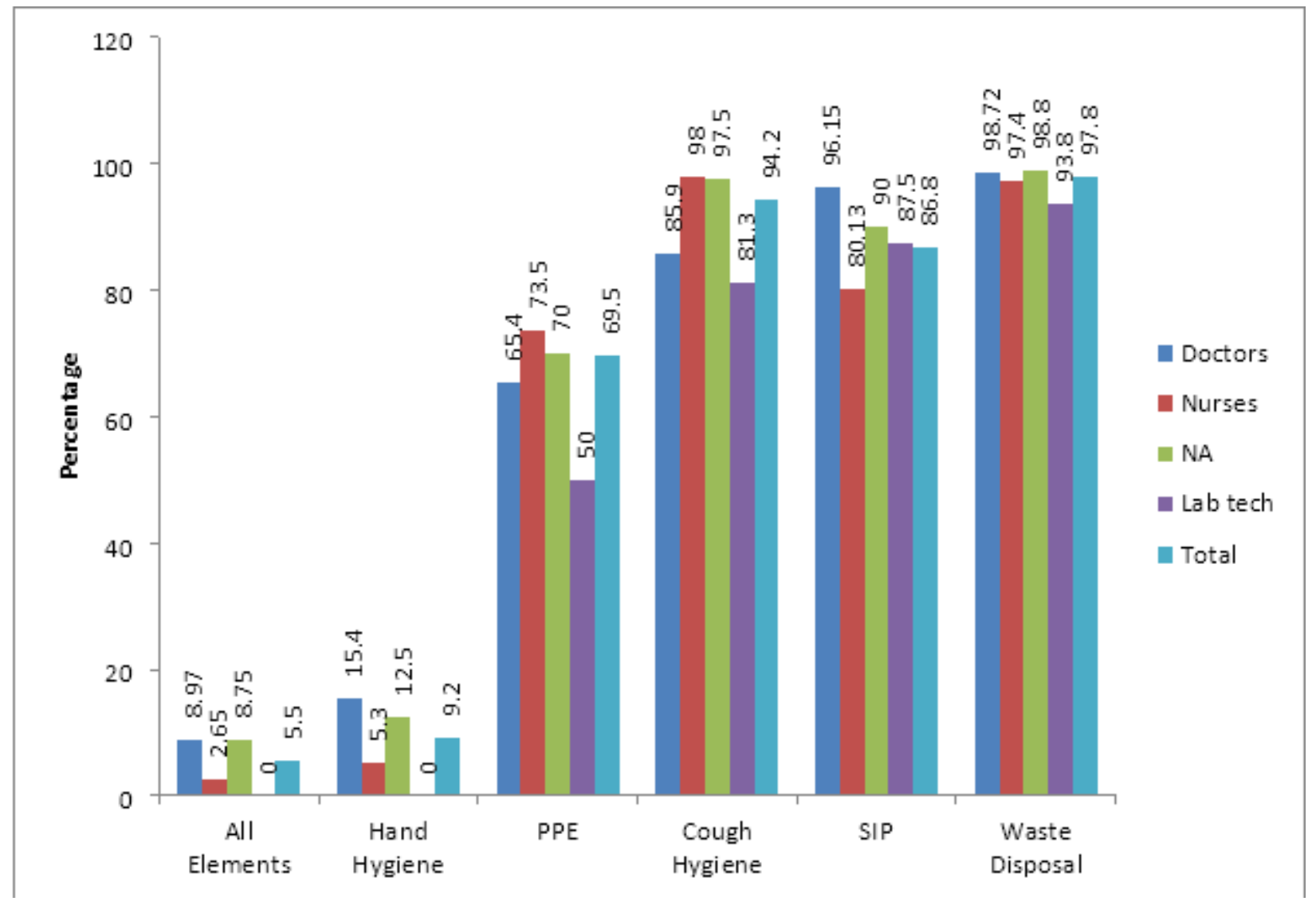

Figure 2

Practice of standard precautions 